\title{
FROM "SAPIENZA" TO "SAPIENZA, STATE ARCHIVES IN ROME". A LOOPING EFFECT BRINGING BACK TO THE ORIGINAL SOURCE COMUNICATION AND CULTURE BY INNOVATIVE AND LOW COST 3D SURVEYING, IMAGING SYSTEMS AND GIS APPLICATIONS
}

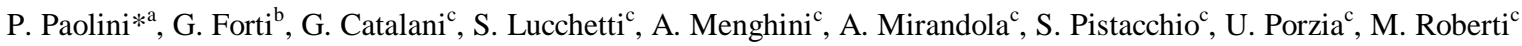 \\ a Dept. of History, Representation, and Restoration of Architecture (D.S.D.R.A), "SAPIENZA" University, \\ 00100 Rome, Italy, researcher, PHD, priscilla.paolini@uniroma1.it \\ ${ }^{\mathrm{b}}$ ESRI Italia, 00100 Rome, Italy, pre-sale manager, geologist, GIS expert - gforti@esriitalia.it \\ c Second Level Degree in Architecture (Restoration), "SAPIENZA" University, 00100 Rome, Italy, student. \\ catalani.1381156@studenti.uniroma1.it, lucchetti.1396473@studenti.uniroma1.it, menghini.1226043@studenti.uniroma1.it, \\ mirandola.1398327@studenti.uniroma1.it,pistacchio.1245823@studenti.uniroma1.it, \\ porzia.1200979@studenti.uniroma1.it, roberti.1051441@studenti.uniroma1.it
}

KEY WORDS: University advanced training, Digital State Archives, Dense Stereo Matching Photogrammetry, Topography, Web Gis Hosting

\begin{abstract}
:
High Quality survey models, realized by multiple Low Cost methods and technologies, as a container to sharing Cultural and Archival Heritage, this is the aim guiding our research, here described in its primary applications. The SAPIENZA building, a XVI century masterpiece that represented the first unified headquarters of University in Rome, plays since year 1936, when the University moved to its newly edified campus, the role of the main venue for the State Archives. By the collaboration of a group of students of the Architecture Faculty, some integrated survey methods were applied on the monument with success. The beginning was the topographic survey, creating a reference on ground and along the monument for the upcoming applications, a GNNS RTK survey followed georeferencing points on the internal courtyard. Dense stereo matching photogrammetry is nowadays an accepted method for generating 3D survey models, accurate and scalable; it often substitutes 3D laser scanning for its low cost, so that it became our choice. Some $360^{\circ}$ shots were planned for creating panoramic views of the double portico from the courtyard, plus additional single shots of some lateral spans and of pillars facing the court, as a single operation with a double finality: to create linked panotours with hotspots to web-linked databases, and 3D textured and georeferenced surface models, allowing to study the harmonic proportions of the classical architectural order. The use of free web Gis platforms, to load the work in Google Earth and the realization of low cost 3D prototypes of some representative parts, has been even performed.
\end{abstract}

\section{INTRODUCTION}

Since almost a decade the Sapienza State Archives in Rome host the Survey training for students of Architecture of SAPIENZA University. Therefore, the architectural harmony of the Classical double order of arcades facing the courtyard acts as the model to be read and synthesized by all the different "measuring" techniques, from free-hand eidotypes until the latest non-contact methods.

In the last few years, Photography, turning to digital, and so likely Photogrammetry, have both come back to being considered as high quality means to represent and study Architecture as much as Archaeology and Cultural Heritage.

Taking advantage of the opportunity, to teach up-to-date surveying technologies and applications, directly experienced by any single student, it actually seems that digital cameras (such intending for Reflex, Bridge or high-res Compact cameras ) applied for Dense Stereo Matching Photogrammetry, thanks to the instrument low cost type, as compared to the expensive as accurate 3D laser scanning systems (the departmental instrument limited access to PHD students and researchers keep it often too far from sight for College students), are the best tools to obtain 3D survey models, scalable and measurable and accurate enough to allow even the materialization of related $3 \mathrm{D}$ prototypes.

The same base intent is to involving more Computational photography techniques, Panography at first, to act as a vehicle, linking and communicating any kind of database differently collected, there creating hotspots either to Archives databases, or to its 3D navigable survey models, or to Gigapixel zoom-able and measurable pictures of engravings and precious books and to 2D drawings and studies, or links to Linked Open Data from further national institutions or from others abroad.

The Director of the State Archives, prof. Paolo Buonora, has been the manager of the "Imago II" project, whose equipe realized from years 1997 to 2000, through 5000 digital colour photos, 25.000 colour scans and 100.000 grayscale scans, a complex database of the most consulted antique archived documents. The intention was to grant preserving the originals of cadastral maps, parchments and notarial registers, and to allow the easy access, since May 2002, to their high resolution digital copies (in MrSID format), thus transformed into Linked Open Data, accessible via the Archives web site.

\footnotetext{
* Corresponding author
} 
From such an important change, it naturally derived the idea of this project, targeted to create by digital Stereo Photogrammetry integrated with other Computational Photography techniques, a Web accessible 3D interactive model of the Sapienza building, as a manifold to connect all different stored databases and as a link to documents from other Archival Funds, thus improving their consultation, access and diffusion, and promoting in parallel the knowledge and fruition as National Cultural Heritage of the important historical building hosting them.

Structured on the integration of applications as described above, it would be projected for the final web user, so organized as a tree structure, where main branches indicate/allow the access to different Archives dataset, (distinguished according with user categories); secondary branches act as cloud platforms by providing specific products (Gigapixel-measurable and editable, HDR images, or even GIS queries etc.) and leaves standing as final data repositories.

The pilot project here described, introducing the start point of the work, is generally based on Low Cost solutions and mainly acts as a training ground for students to produce accurate and scientific results. The Low-cost finality must be intended either as Cost-saving, thanks to the use of affordable instruments and software (e.g. personally owned compact cameras, Agisoft SW Educational licenses purchased by students, as much as ESRI free ArcGIS platform access and base maps use) or Timesaving, trying to structure parallel workflows aimed at various results by the elaboration of a single, common database.

The final use and diffusion of the produced multi-resolution and integrated data will rely on some Free Web space Hosting (Google Drive free web space for SAPIENZA University) and maybe in the Archives web site and its usage will be even more implemented as imported by links inside free applications of GIS platforms (ARCGIS Online).

\section{THE PILOT PROJECT, PARALLEL AND CORRELATED WORKFLOWS}

\subsection{Topographic Survey and GPS Survey}

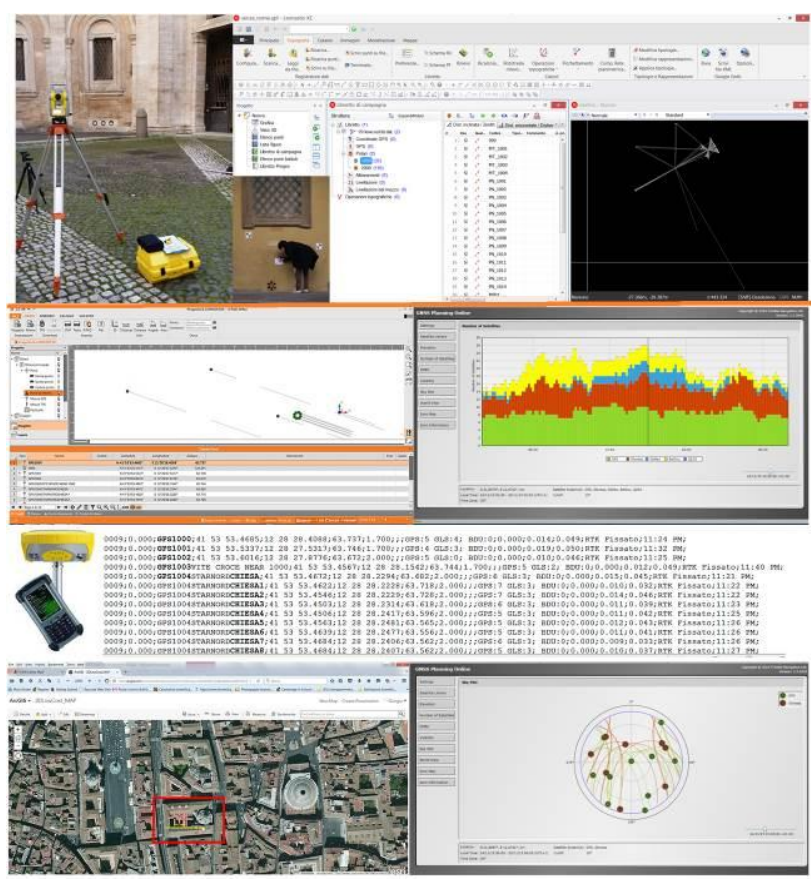

Figure 1. Topographic and GNNS survey
The topographic survey by Total Station was focused on the measuring of some geometric references along the building, as details for the future scaling of all the 3D survey models. Furthermore some black and white topographic targets were measured for model georeferencing together with some photogrammetric coded targets (Photoscan Pro software sensitive) useful for Dense Stereo Matching activity. The materialization of ground points distributed along the courtyard was completed by a GNSS survey campaign, such creating multiple georeferenced points for exporting the final models to Web-Gis and to Web (Fig.1).

For the GNSS survey it was used a Geomax Zenith 25 Pro receiver in RTK mode (supporting GPS, GLONASS, Galileo, BeiDou and SBAS systems-Quad-band GSM \& Penta-band; accuracy: $\mathrm{KH} 10 \mathrm{~mm}+-1 \mathrm{ppm}$, KV 20mm +-1ppm; rms), the planning for defining the survey date and time, used an online platform (http://www.gnssplanningonline.com/\#/Settings) from Trimble. To check the satellite positioning, we set Latitude and Longitude of site coordinates, fixed a cut off of $10^{\circ}$, in a range of 6 hours, aiming at the visibility of at least 9 satellites. The sky plot confirmed the presence of a tenth of satellites around midday of the day scheduled for. The survey succeeded, fixing the cut off at $15^{\circ}$, because of the courtyard very small field of view. In 8 minutes were surveyed 13 ground points receiving a range from 5 to 7 GPS and from 3 to 4 GLS satellites, the limit set for accuracy was at $50 \mathrm{~mm}$ max range $\mathrm{H}$ and $\mathrm{V}$, the achieved one was between 09 and $19 \mathrm{~mm}$ Horizontal, while 32 and $49 \mathrm{~mm}$ Vertical. Differential correction techniques were used to enhance the quality of location data gathered, applied in realtime directly in the field by a connection to the regional georeferencing system "Rete GNSS Regione Lazio" (http://gnss-regionelazio.dyndns.org/Spiderweb/frmIndex.aspx) using as Base reference the station named: ROMA, Code: ROUN, RTCM-Ref 9; (receiver Leica GR10, sampling interval:1 second).

2.2 Computational Photography for CH communication and digital Photogrammetry for scientific application: a joined role.

\subsubsection{The $360^{\circ}$ main shooting sets Project}

Planned to create the base representation of the whole building by a cluster of navigable panographies (nowadays the entire series involving upper floors is not yet completed), acting as the reference for linking any database and survey model, the first $360^{\circ}$ shooting sets were realized at ground floor, along the courtyard core. The first set, as the main, was centred at East (Fig.2),

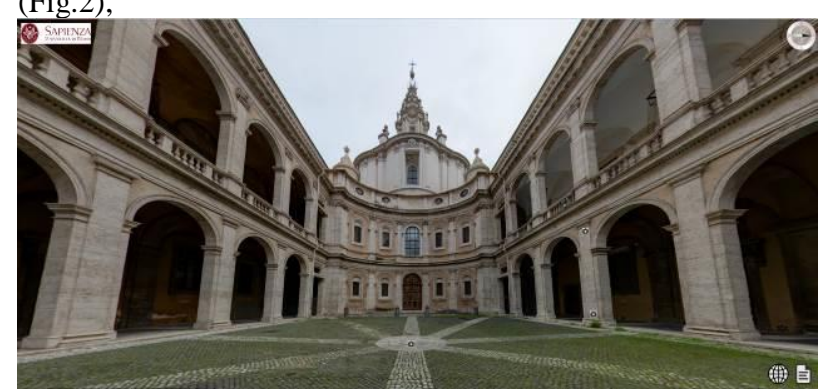

Figure 2. Panotour with hotspots to architectural 3Dmodels

near to the S. Ivo church façade, four more sets were positioned at west in the court, near to the main entrance, each one planned to be in direct visual contact with some lateral spans, where additional shooting sets (both types: $360^{\circ}$ and 
single shots) were realized in parallel, to be linked to each other by hotspots. The applications from the courtyard attempted at first the positioning of the camera at 10m (along the longitudinal axis of court) and then nearer at $7 \mathrm{~m}$ and $5 \mathrm{~m}$ from the main surface, oriented by circular array towards the surrounding double order of arcades and including all the visible structures from ground to top.

Such operation, was performed by using a high resolution digital SLR camera, full frame, 22.3MP, with $15 \mathrm{~mm}$ fisheye lens, levelled and fixed on a spherical panoramic head with rotator and mounted on tripod (Canon 5D Mark III; EF 8$15 \mathrm{~mm}$ F/4 L Fisheye USM; Nodal Ninja 5 on Advanced Rotator; Manfrotto tripod). It was oriented in Portrait view (FOV: $91^{\circ} 46^{\prime} \mathrm{H} \times 142^{\circ} \mathrm{V}, 175^{\circ} 30^{\prime} \mathrm{D}$ ), focused at hyper focal distance (depth of field from $68 \mathrm{~cm}$ to $\infty$ ) and used bracketing tool (5 shots each $1,1 / 3$ stops) to realize exposure fused images, to avoid any under/over exposed area, not readable then to DSM software ${ }^{1}$, charged for the 3D point clouds extraction. From any shooting station have been realized 6 shots at $60^{\circ}$ interval each (at $90^{\circ}$ Zenith) with a $34 \%$ side overlap and camera positioned on the no-parallax axis (lens entrance pupil), plus 2 at $0^{\circ}$ Zenith and 2 at $0^{\circ} \mathrm{Nadir}$, with $+/$ $180^{\circ}$ rotation for both. 2 Nadir shots were added, by positioning the camera levelled and oriented on ground reference point, with tripod adequately shifted $80 \mathrm{~cm}$ away from, to avoid the tripod legs presence on the nadir picture for the stitched equirectangular panorama. It was worth calculating the pictures resolution, related to the exact object distance from the camera, as referred to the real building dimensions (scale value), so to obtain a very enlargeable tiff image for Virtual Panotour and a database with enough resolution (besides a good relative overlapping) for 3D surface model calculation by Dense Stereo Matching procedure. (Fig.3)
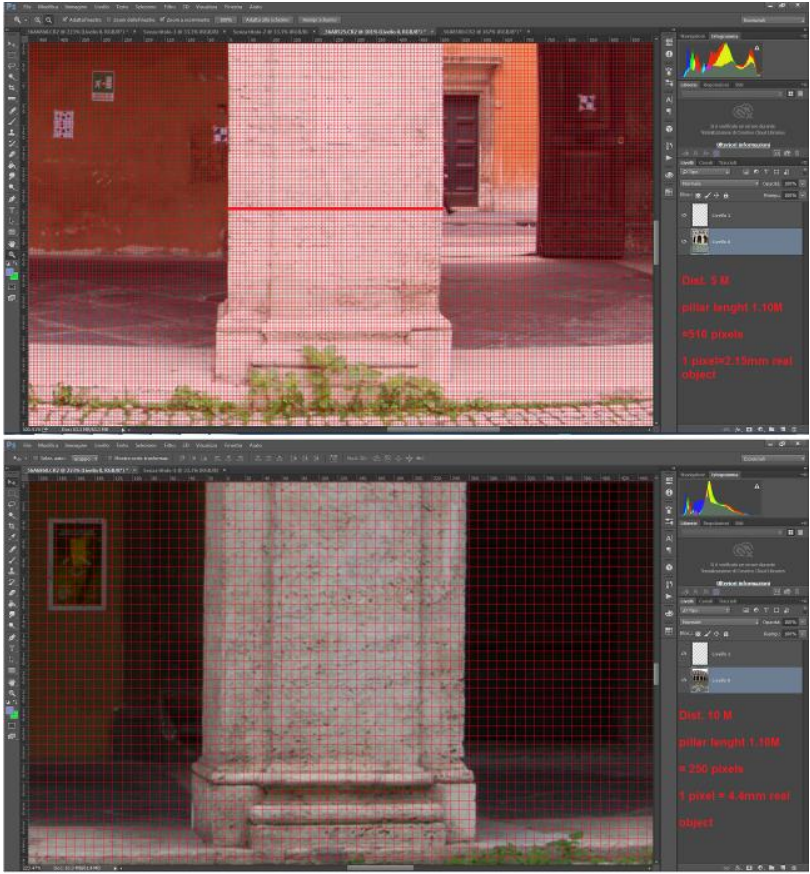

Figure 3. Image resolution VS real object size

The images resolution, as referred to real dimensions, was: for the first set at East, $10 \mathrm{~m}$ far from the portico, 250 pixels in $1.10 \mathrm{~m}$ (pillar front size), one pixel corresponding to $4.4 \mathrm{~mm}$ of real object, allowing a scale of 1:22 (for 2D drawing rendering). For pictures at west of court, taken at $7.20 \mathrm{~m}$ distance, 370 pixel in $1.10 \mathrm{~m}$, one pixel $=2.97 \mathrm{~mm}$, resolution scale 1:14.85; while for shots taken at $5 \mathrm{~m}$ distance, $\mathbf{5 1 0}$ pixels in $1.10 \mathrm{~m}$, one pixel $=2.15 \mathrm{~mm}$, resolution scale $1: 10.75$. (Fig.4)

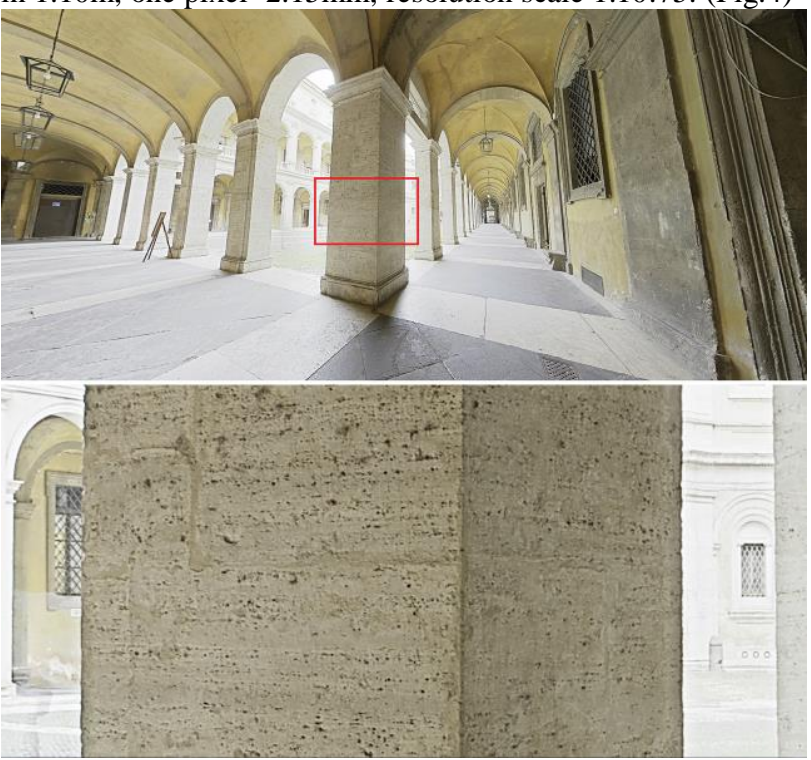

Figure 4. The SW angle span Virtual Tour tight zoom factor

The following sets were applied on some spans at intrados, along the portico at ground floor, two at SW and NW (angle spans), one at $\mathrm{W}$ (central span) of building. The shooting used the identical settings as before said, but being the camera centred inside of each span measuring $6 \times 4 \mathrm{~m}$, so near to the wall, any image reached a high pixel resolution. These pictures, taken at $3 \mathrm{~m}$ distance, reached a scale of 1:7.45, getting 740 pixels in $1.10 \mathrm{~m}$, one pixel corresponding to $1.49 \mathrm{~mm}$ of real object. From this derived the relative hyperresolution of each tiff equirectangular image allowing on the Virtual Tour a tighter zoom opportunity, becoming the best 3D base model for linking all the stereo digital models of details taken by action cameras and compact cameras.

In addition some single shots were realized by action cameras around the intrados of three spans at southwest and around each of their relative (four) pillars facing the courtyard, but very near to each other, reaching a $50 \%$ side overlap (as needed for DSM modelling). The expected results did not arrive immediately, since the equirectangular tiff images, following on after exposure fusion, de-ghosting and stitching processing of each spherical shooting set, had not enough resolution to produce a $3 \mathrm{D}$ point cloud model. Not even the single pictures highly overlapped, taken inside each span and around pillars, worked as a link, some of them being over exposed (the action cam and the compact camera could not control exposure perfectly) so not visible enough to the software. Maybe there was even a problem of noise (to high ISO values), causing misalignment and inhibiting the elaboration of dense point cloud. But the attempt of using the panoramic images as a Wide field of view in which to include any more detailed set, focused on objects by a nearest distance, was successful. Of course the problem was the sampling resolution of homologous points in each picture set, being not

${ }^{1}$ Agisoft Photoscan Pro 1.2.2 x64 


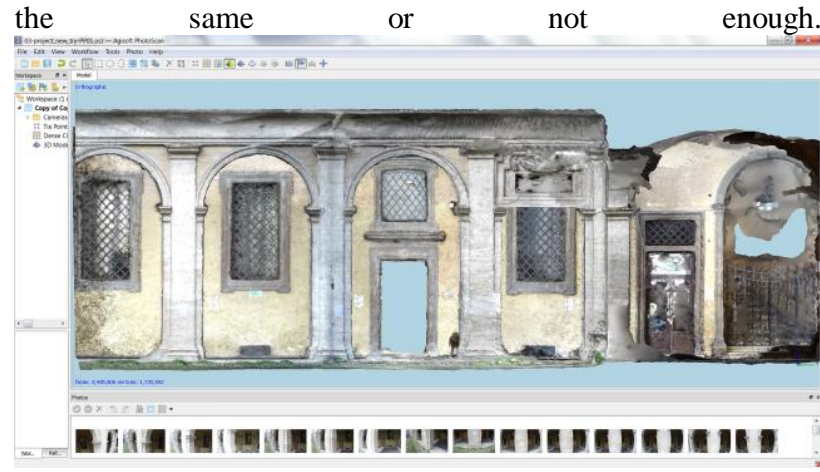

Figure 5.Photoscan 3D textured surface model

An acceptable solution (Fig.5) was found using the $360^{\circ}$ pictures taken inside the spans, so having a higher resolution, but using its tiff images (each of 22.3MP) separately and not unified in a single panoramic tiff image with a lower resolution. From the connection of "Chunks" of these shot series and of some more grouping single shots taken by action cams (lower resolution but more overlapped in vertical as in horizontal direction) focused on single parts, having the merit to reach highest architectural details as mounted on a $4.50 \mathrm{~m}$ extendable rod and shot with enough overlapping field. The resulting mesh textured model (elab.: medium complexity) (Fig.6) unified 3 sets of images at $360^{\circ}$, one from the court and two from spans at intrados has 3,435,506 faces and 1,702,592 vertices.
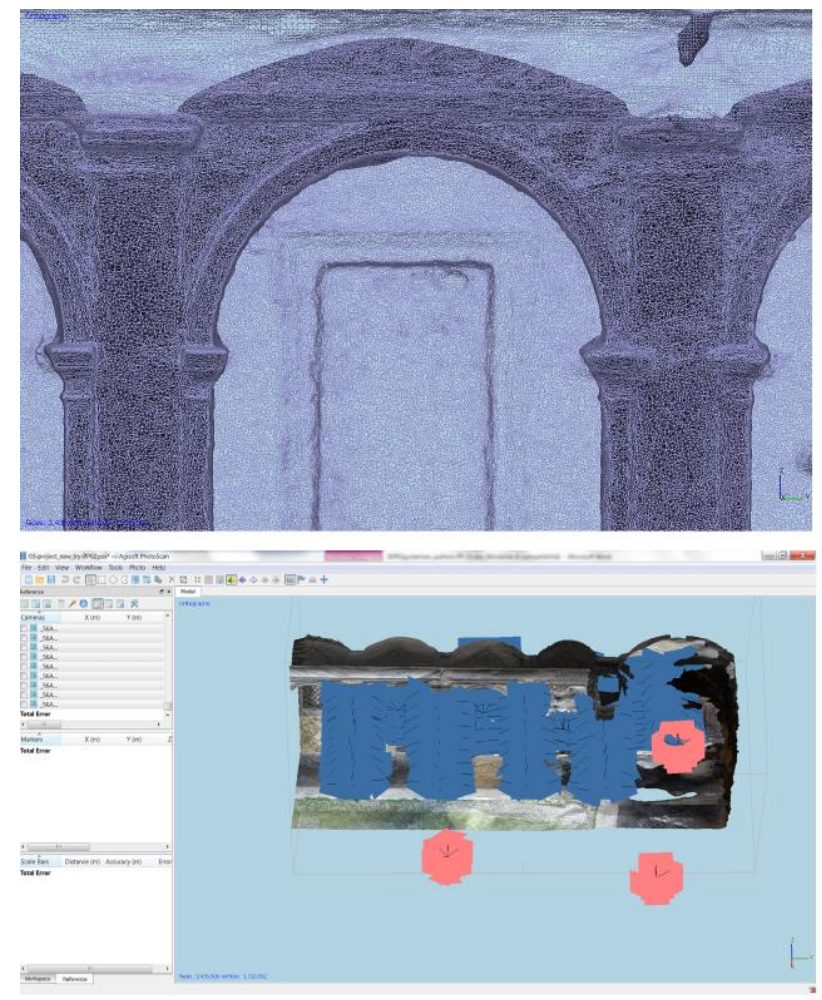

Figure 6. Frontal view of triangulated mesh, shadowed the vaults intrados profile. In pink the $360^{\circ}$ shots, in blue the groups of single pictures

This was the base to which have been referenced and linked all the single shots taken around the pillars.

\subsection{Dense Stereo Matching Photogrammetry applications on more details}

Some additional procedures projected for the realization of Photogrammetric 3D survey models were applied on some specific architectural and carved details: either the Boncompagni family emblem, facing the sopraporta on the first South West lateral span, either the eight pointed heraldic star of the Chigi Family moulded in the manhole covers of the double impluvium in the courtyard, or a whole pillar and more pillar bases and capitals. The multiple model shooting experience aimed at comparing Photographic low cost instruments, different for sensor resolution and technical characteristics (automatic settings and not), while studying on each one a different argument for the final 3D model construction by DSM photogrammetry elaborations. All of the realized procedures were integrated by topographic survey and/or GNSS survey for allowing the referencing and scaling of each surface textured model, to produce 2D drawings and allow the measuring or georeferencing, as it will be further explained.

\subsubsection{The Boncompagni emblem model: standards and survey project}

Between the many case studies provided by the "Palazzo della Sapienza" for testing low cost surveying applications, it was selected the Boncompagni family emblem (Fig.7)

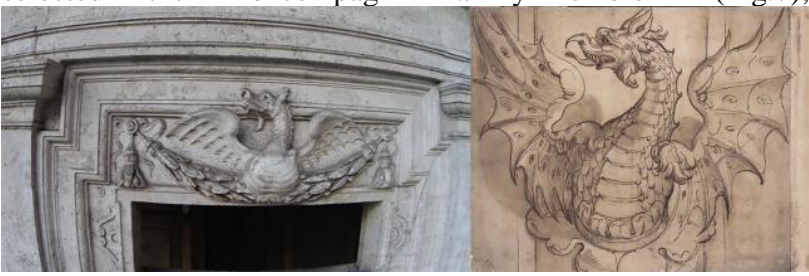

Figure 7. The Boncompagni heraldic emblem on lintel; a dragon with scaly outstretched wings designed for the Pope

Gregorio XIII from B. Passerotti in 1572 (orig. sketch)

a travertino stone sculpted dragon, an organic geometry detail on the southwest corner of the courtyard, decorating the sopraporta of the first lateral span, showing itself at about 6 meters from ground. Since the survey is a dynamic process ${ }^{2}$ that evolves and adapts itself according to any sought purposes, it was decided to adopt the Dense Stereo Matching technique, in order to get much suitable models ${ }^{3}$ for scientific research, as the simple disclosure. A Sony FDR X1000V, 8MP digital action camera was applied, as chosen for its ease of use, for the Zeiss lens quality, for the provided image stability system (steady shot) and for the Wi-Fi shooting option by a mobile App. The camera (equipped with a CMOS sensor 16.6 × 4.6 $\mathrm{mm}, 2.8 \mathrm{~mm}$ fixed focal length, crop factor 1.17 , AOV $108^{\circ}$ ) mounted on a telescopic graduated rod with a built-in level, was placed at about one meter away from the object, covering with a single shot an area of $2.2 \times 1.2 \mathrm{~m}$ and developing a scale of frame greater than 1:5. (Fig.8).

Prior to Image Matching procedure, the photographic campaign considered the distribution of the photos along the Cartesian axes and their orientation in space relatively to the object shape, aiming at leaving no gaps. With respect to the sculpture main front facing the courtyard, the number of 3 ground stations was executed from which to acquire 3 sets of

\footnotetext{
2 Docci M., Maestri D., Manuale di rilevamento architettonico e urbano, Bari, 1994, pagg. 57-74

Migliari R., (a cura di), Prospettiva dinamica interattiva, Roma, 2008, pagg. 7-10
} 
77 shots in total at 11 different heights (22 stations at the right and left sides and 33 at center) with an overlapping of about $50 \%$ between each picture. To be able to scale the model it

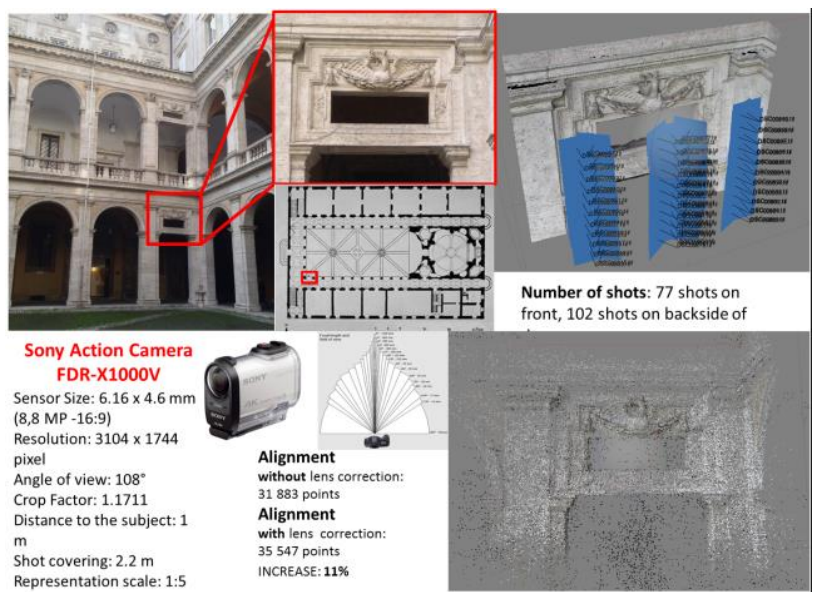

Figure 8. shooting and processing phases

was decided to measure by laser Disto $^{4}$ the edges of the sopraporta hole below the dragon. In order to facilitate the proper identification of frames in post-production phase, it has been appropriate to acquire them in bright indirect light conditions, in total absence of shadows: this expedient is consistent with the technical specifications of the provided equipment, because of the camera automatically calculating the exposure time. A following set of 101 more pictures of the back and internal parts of the object frame, following the same above mentioned rules, allowed the final completion of the total 3D model.

\subsubsection{Processing and conclusions}

It was possible to verify that the preliminary operation to perform at any stage of the photogrammetric process, focused at optimizing the extraction of the point cloud, is the correction of the optical aberration ${ }^{5}$ of each captured frame, due to the physical nature of the lens, in this way all the pixels more warped and poor of information, laying at the edge of each shot, will be deleted. Thus in the images alignment phase, the software identification of the points has increased of 10-11\%. In fact, by using in both tests medium settings, the software processes frames with optical aberration identifying only 31.883 homologous points; while providing the program with frames with the appropriate lens correction, it calculates 3.664 more homologous points. With regard to the generation of the point cloud, it was not detected any noteworthy improvement, as a result of the above mentioned corrections. In detail, the

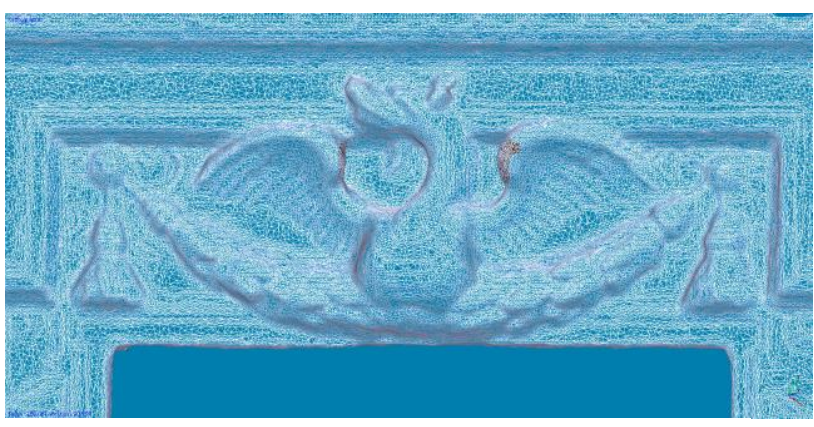

Figure 9. Detail of the triangulated mesh model

\footnotetext{
${ }^{4}$ Leica Disto D2

${ }^{5}$ Adjustment made with Adobe Photoshop Lightroom 6.2
}

dense point cloud computed 1.960 .964 points on RGB data, while the mesh counts 396.184 triangle faces and 198.536 vertices.(Fig.9).

The time required for acquiring all data was about 35 minutes for the front side and 30 for the back side and internal parts, thanks to the equipment ease of use, while the operations of data processing varied depending on the level of accuracy to be achieved: having set the calculation software ${ }^{6}$ with basic settings, the machine used in this test ${ }^{7}$, ran the process in about 20 minutes for each side, while the parameters calculation average processing time took 3 times more, but recognizing five times more data. Not less important was the focus on the purely economic aspect of these photogrammetric operations, since the equipment used for the data acquisition has a value that, compared to that of laser scanning systems, is much cost saving. It is nevertheless clear that for objects of small size the gap between the two systems is out of proportions, while it tends to shrink when applied on studying the whole architectural complex.

2.3.2 The Chigi eight pointed star emblem: 3D Photogrammetric model and GNNS survey references

The double manhole cover centred at each of the two halves of the court, marks the drainage for rainwater to the articulated underground of the building.
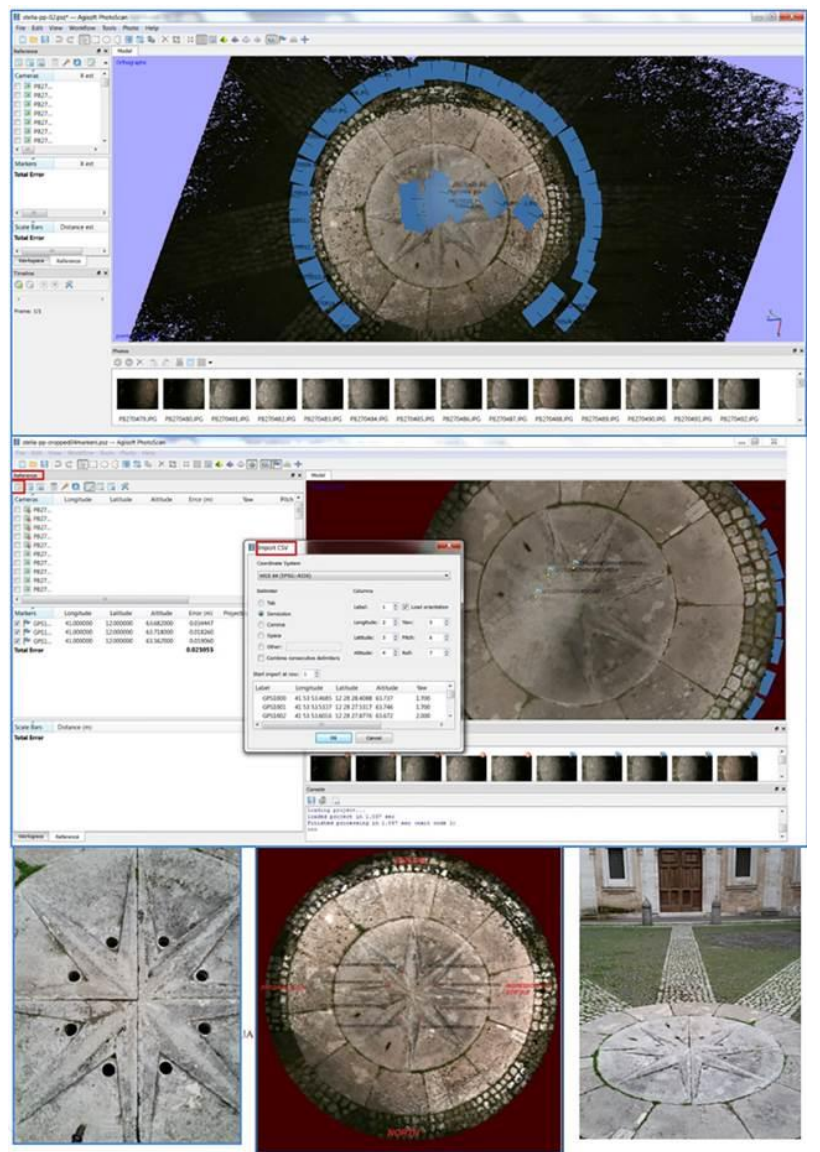

Figure 10. Chigi emblem: dense stereo matching elaboration

The star, sculpted in a travertino marble disk of $1.85 \mathrm{~m}$ in diameter, surrounded by a circular flat band of $60 \mathrm{~cm}$, is divided in quarters lightly sloping toward the centre, aligned to the longitudinal East West axis of the building. It has been part

\footnotetext{
Agisoft Photoscan Professional 1.2.2

MacBook Pro Early 2011
} 
of the survey project for the shape and position it has, either for testing photogrammetric shooting set without the use of tripod either to allow a very accurate georeferencing.

The operation started using a compact camera Olympus VR 360, 16MP (4612x3468), CCD sensor size $(6.16 \times 4.62 \mathrm{~mm})$. Focal length 24-300mm, aperture f/3-f/5.9; exposure compensation $-2 \mathrm{Ev}+2 \mathrm{EV}$ with $1 / 3$ steps, auto ISO and digital metering. (Fig.10)

By 47 pictures taken at $1 \mathrm{~m}$ distance from ground, focal length $4.20 \mathrm{~mm}$ ( $24 \mathrm{~mm}$ ref. to $35 \mathrm{~mm}$ ) aperture $\mathrm{f} / 3$, ISO 200 , in jpeg large format (exif data), the shooting ended up in 6 minutes. We achieved almost a total image overlapping, due to the small dimensions of the piece and to the $84^{\circ}$ field of view of the corresponding focal length.

A specific camera calibration test was requested, so to import the profile before the beginning of alignment operations (sw: LENS Agisoft, free). The frames resolution is of 2740 pixel in $3.10 \mathrm{~m}$, resulting in 1 pixel $=1.1 \mathrm{~mm}$ of real object, allowing a scale of 1:5 circa. Imported the images first, then the camera profile, the alignment begun lasting 10 minutes, then the dense point cloud generation quality set to medium and moderate depth filtering, brought the elaboration to end in a few. The procedure ended by aligning 46 of 47 pictures, generating a dense cloud of 1,281,427 points and a mesh of 150,788 faces and 75,895 vertices. The following operation edited specific markers on model, corresponding to the eight concave angles of the star. There it was previously realized a GNSS survey, which more than surveying the ground points selected as bases for panoramas shooting and for topographic survey, was applied on to measure these references on star at ground. The import of the survey coordinates allowed to export the textured 3D model in KMZ format and load it into Google Earth, such making it as the confirmation of the possibility of importing any 3D survey model coming out of digital dense photogrammetry into the web.(Fig.11)
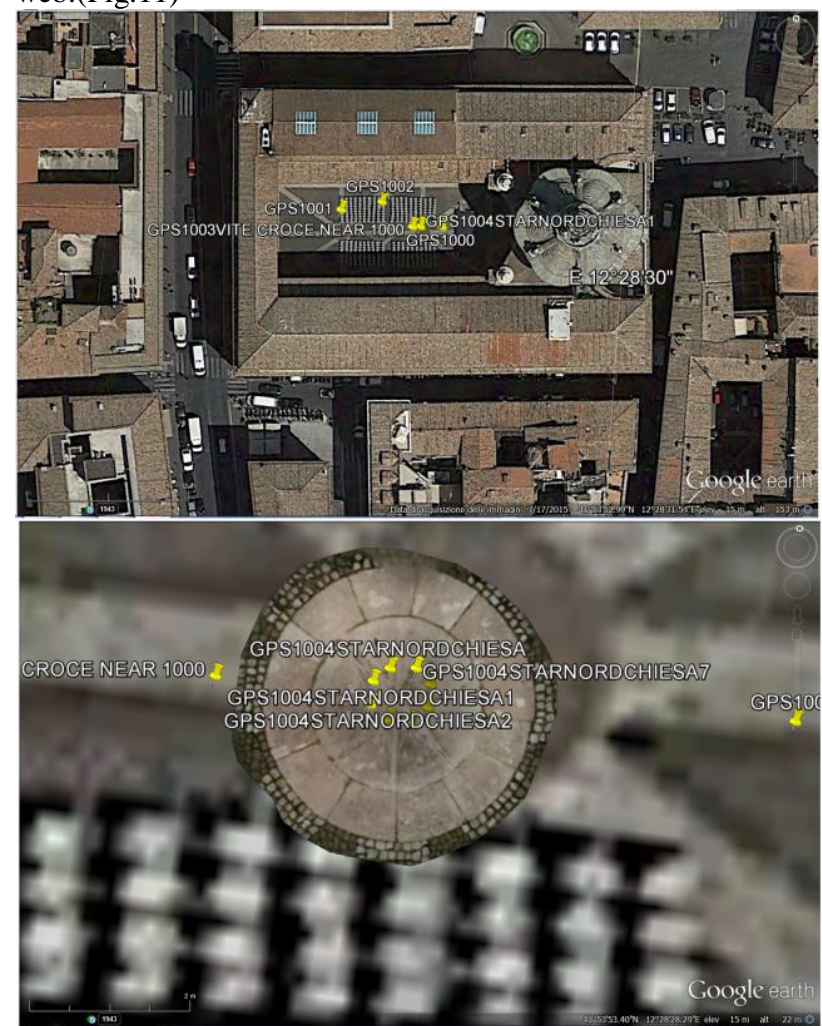

Figure 11. Chigi emblem KMZ format import in Google Earth

\section{3D PROTOTYPING: THE BONCOMPAGNI DRAGON MODEL SETUP.}

The 3D printing (3DP) or additive manufacturing of the whole, or of some architectural parts and details of the building, by utilizing .stl or .obj file format (derived from DSM photogrammetry project) and software and technologies low cost, will be finalized to be used by different kind of "prosumers"(prototype-consumers).

A physical 3D model reproduced by 3D Printing can be obtained either by means of the technology called FDM (Fused Deposition Modelling, Pat. Stratasys 1990), or by the one called FFF (Fused Filament Fabrication, since 2010), similar to the previous one but resulting from an Open Source project, and born after the expiring of Stratasys Company patent. In detail the system creates a 3D object by the fusion and extrusion of a thermoplastic filament in ABS (Acrylonitrile Butadiene Styrene) or PLA (Polylactic Acid), Thermo Polymers with very reasonable prices; it applies drawing by layers on a printing plane, melting this solid plastic. For the low cost granted by the open sourcing of these technologies and by the opportunity for everybody to refer to prototyping services at low cost, it was worth to include this experience inside this project.

About the final physical prototypes, they can be employed for multiple finalities: as substitutive replicas of monuments or environments not accessible to the public or too extended to be visited in one single session, for the construction of tactile and simplified paths for blind or handicapped people; or as versatile tools in precincts of maintenance and restoration of Cultural Heritage, being able to rebuild a faulting portion of a stucco moulding, or part of a marble statue or a bas/high relief, or lastly as a gadget for merchandising.

We aimed at verifying if, by using a DSM photogrammetric ${ }^{8}$ model, it is possible to generate a virtual 3D copy that requires only a rapid and easy refinement before being ready for the $3 \mathrm{D}$ printing process.

Getting more in detail, we are going to make some observations about our test-object shooting results and defects. During the photographic acquisition of the Boncompagni dragon, some areas resulted to be not easily reachable or were under exposed; such affecting the subsequent tri-dimensional modelling result. Indeed the analysis of the obtained model, showed that the surface was affected by 17 leaks along the edges, (Fig.12)

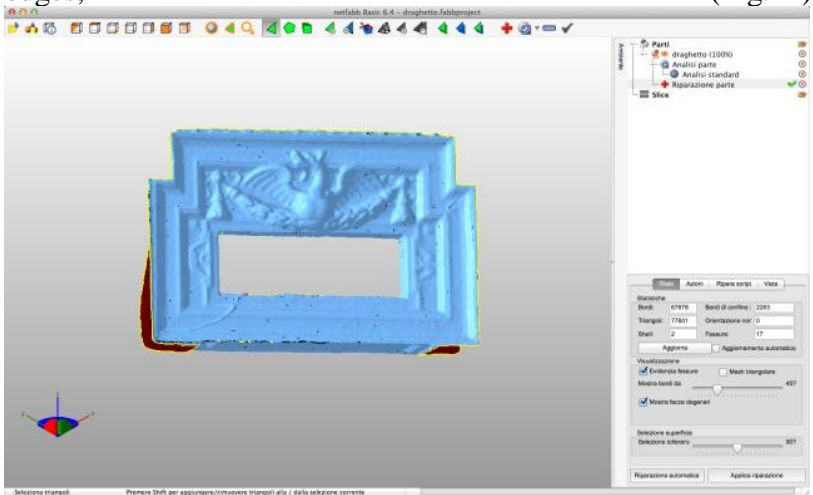

Figure 12. Netfabb: selection of model leaks to be recovered

fully recovered by a free software ${ }^{9}$ able to handling of files in stl format and able to apply an automatic repair, utilizing the

8 Agisoft Photoscan Professional 1.2.2

9 Netfabb Basic 
same interface as the Professional release. We checked then the tridimensional printing parameters with $^{\mathbf{1 0}} \mathrm{a}$ G-code generator for 3D printers (http://slic3r.org/)(Fig.13), which works sectioning the model into horizontal layers; it then generates toolpaths to fill each of them and calculates the quantity of Polymer to be extruded. In our project we used the following parameters: print scale 1:10, layer width of $0.2 \mathrm{~mm}$, solid layer at $4 \mathrm{~mm}$ for the bottom and $5 \mathrm{~mm}$ for the upper part, infill $25 \%$ using the honeycomb matrix to guarantee a better solidity of the structure.

The first tridimensional print led to the production of a prototype that was affected by a suboptimal resolution in the most important particulars. In the more protruding areas of the model, printing layers did not guarantee the full readability of the model, so we chose to change the layer thickness to 0.05 $\mathrm{mm}$, which represents the highest resolution of the printing. The second tridimensional print, with the changed layer width, produced a prototype with the correct resolution. The problems arising from 3D prototyping through the use of stereophotogrammetry model can be restricted only to the integrity of the models resulting from the survey. Here we showed that it is possible to correct and integrate the obtained models with open source software, thus resulting in reduced time for the final prototype elaboration.

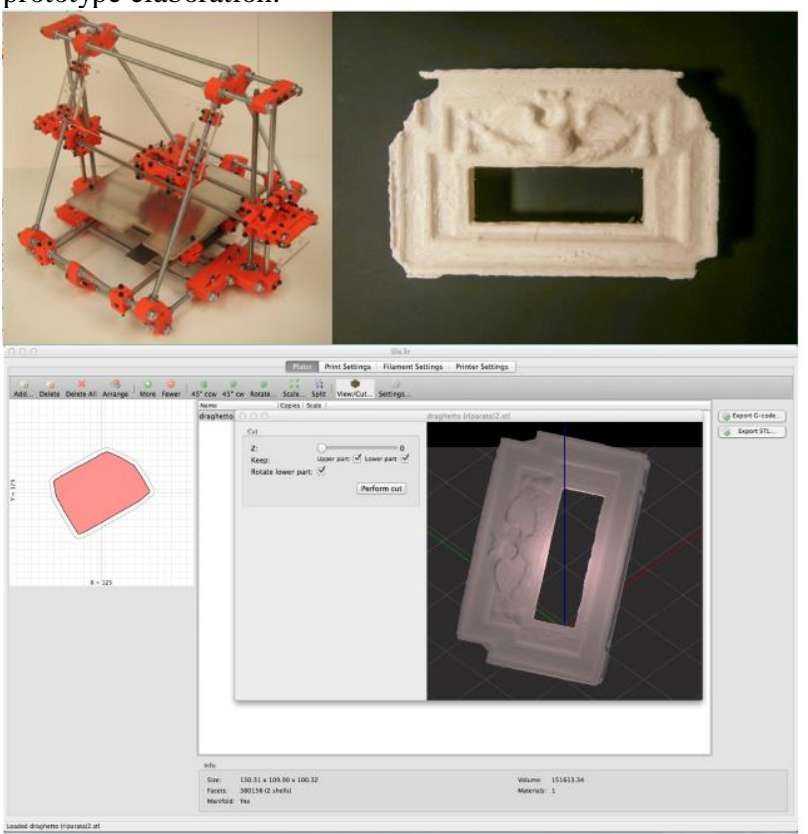

Figure 13. Slic3r: layering the model for RepRap print

Printing was executed with a RepRap 3d printer, the first of the low-cost 3D printers (open source project), the total cost of the printing has been of 15 euros for a model in scale 1:10.

\section{WEB HOSTING AND WEB GIS APPLICATION:}

For a complete usage of the $3 \mathrm{D}$ models mentioned before it was decided to organize them to be used in a web-mapping application inside the ESRI Cloud platform, ArcGIS Online, that in addition to the Organizational account type, it has one of Free access. That leaded our choice, cause even if with limitations, it permits the creation of a map with the geo-

10 Slic3r Release 1.1 .6 localisations of the 3D textured models and of a web application hosting them.

Using these GIS capabilities, we have created a 2D navigable web application based on a predefined and customizable Template in which at each geo-localisation we have associated a Hyperlink that activates any content so to allow either database download, or even the fruition of Computational Photography products (as Gigapixels, Panographies, HDR images, Tone-mapped images of documents or other), or links to historical cartography and docs, as much as the interactive visualization of 3D survey models and prototypes.(Fig.14).

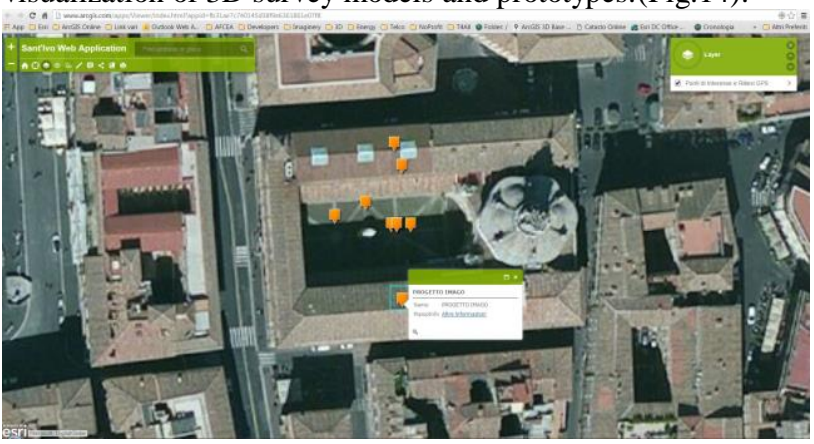

Figure 14. Web application published in ArcGIS Online

For generating this application it's not necessary to have programming skills in Web JavaScript language, it's sufficient to use one of the predefined Templates. The web app is hosted in the ArcGis Online Cloud and the source code can be downloaded and modified. The web app can be shared in public mode and therefore everyone can access to it through a short URL. With the "Map Viewer" environment it's possible to modify the map and this allows that the web application, that uses this map, is automatically up-dated.

Furthermore, it's possible for any user to visualize by the free Client 2D/3D ArcGIS Earth, release 1.0, (released on the date of publication of this paper), the 3D models in their cartographical contest imported in KMZ format, in addition to the maps previously published in ArcGIS Online.(Fig.15)

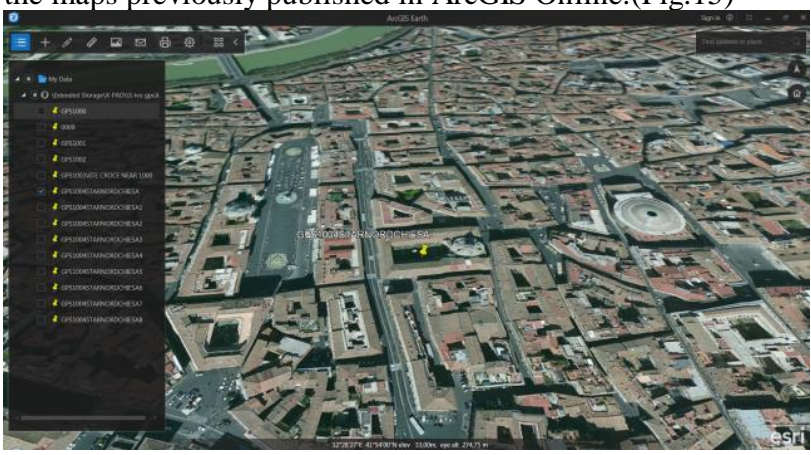

Figure 15. ArcGis Earth, geo-referenced KMZ survey models

\section{CONCLUSIONS}

The pilot project experience will continue in these days bringing us to repeat all the operations that can be improved. First of all there will be a new $360^{\circ}$ shooting series along the court, focused on achieving the highest resolution as possible, maybe the use of a different lens from the $8-15 \mathrm{~mm}$ fisheye could help. Even the overlapping will be increased noting that the $30 \%$ overlap, retained as suitable for building panoramic images, is not enough to realize on the same database a photogrammetric 3D model. The problems observed in the fault of definition in some pictures will be solved by the use of 
focus stacking technique, such focusing on each surface singularly to grant the readability of farthest details.

\section{ACKNOWLEDGEMENTS}

Our gratefulness to the Director of State Archives, that is not only our generous host, but even demonstrated his interest in our project, himself working since years on scientific research for improving the sharing of Big Data by the open minded consideration of any opportunity.

A special thanks to the Agisoft support equipe, specifically to Alexey Pasumansky, without which collaboration and competence many of the positive results in large scale project application wouldn't have come out.

\section{REFERENCES.}

Baik, A., Yaagoubi, R., and Boehm, J., 2015. Integration of Jeddah Historical BIM and 3D GIS for Documentation and Restoration of Historical Monument, Int. Arch. Photogramm. Remote Sens. Spatial Inf. Sci., XL-5/W7, 29-34, doi:10.5194/isprsarchives-XL-5-W7-29- 2015.

Barazzetti, L., Fangi, G., Remondino, F., Scaioni, M., 2010. Automation in Multi-image Spherical Photogrammetry for 3D Architectural Reconstructions. VAST: International Symposium on Virtual Reality, Archaeology and Intelligent Cultural Heritage-Short and Project Papers, The Eurographics Association, pp. 75-81.

Barazzetti, L., Banfi, F., Brumana, R., Oreni, D., Previtali, M., and Roncoroni, F., 2015. HBIM and augmented information: towards a wider user community of image and range-based reconstructions, Int. Arch. Photogramm. Remote Sens. Spatial Inf. Sci., XL-5/W7，35-42, doi:10.5194/isprsarchives-XL-5W7-35- 2015.

Bujakiewicz, A., Podlasiak, P., \& Zawieska, D., 2011. Georeferencing of close range photogrammetric data. Archiwum Fotogrametrii, Kartografii i Teledetekcji, 22, 91104.

Callieri, M., Dell'Unto, N., Dellepiane, M., Scopigno, R., Soderberg, B., \& Larsson, L., 2011, October. Documentation and Interpretation of an Archeological Excavation: an Experience with Dense Stereo Reconstruction Tools. In VAST (pp. 33-40).

Chiabrando, F., Donadio, E., and Rinaudo, F., 2015. SfM for Orthophoto to Generation: A Winning Approach for Cultural Heritage Knowledge, Int. Arch. Photogramm. Remote Sens. Spatial Inf. Sci., XL-5/W7, 91-98, doi:10.5194/isprsarchivesXL-5-W7-91- 2015.

Colomina, I., Blázquez, M., Molina, P., Parés, M.E. and Wis, M., 2008. Towards a new paradigm for high-resolution lowcost photogrammetry and remote sensing. IAPRS\&SIS, Vol. 37(B1), Beijing, China, pp. 1201-1206.

El-Hakim, S.F., 2006. A sequential approach to capture fine geometric details from images. International Archives of Photogrammetry, Remote Sensing and Spatial Information Sciences, Vol. 36, Part5, pp. 97-102.
Fangi, G., 2007. The Multi-image Spherical Panoramas as a Tool for Architectural Survey. XXI International CIPA Symposium, Athens, XXXVI-5/C53pp. 311-316.

Fangi, G., 2009. Further Developments of the Spherical Photogrammetry for Cultural Heritage. XXII CIPA Symposium, Kyoto, Japan, pp. 11-15.

Fangi, G., Nardinocchi, C., 2013. Photogrammetric Processing of Spherical Panoramas. The Photogrammetric Record, vol. 28, no.143, pp. 293-311.

Grussenmeyer, P., Burens, A., Guillemin, S., Alby, E., Allegrini Simonetti, F., and Marchetti, M.-L., 2015. 3D Recording methodology applied to the Grotta Scritta Prehistoric Rock-Shelter in Olmeta-Di-Capocorso (Corsica, France), Int. Arch. Photogramm. Remote Sens. Spatial Inf. Sci., XL-5/W7, 179-185, doi:10.5194/isprsarchives-XL-5-W7179- 2015.

Guidi, G., Gonizzi, S., Micoli, L., 2014. Image Pre-processing for Optimizing Automated Photogrammetry Performances. ISPRS Annals of Photogrammetry, Remote Sensing and Spatial Information Sciences, vol. II-5, pp. 114-125.

Guo, J., Zhong, R., Zeng, F., 2014. Panoramic Images Mapping Tools Integrated within the ESRI ArcGIS Software. IOP Conference Series: Earth and Environmental Science, vol. 17, no. 1, pp. 1-5.

Hassani, F., Moser, M., Rampold, R., and Wu, C., 2015. Documentation of cultural heritage; techniques, potentials, and constraints, Int. Arch. Photogramm. Remote Sens. Spatial Inf. Sci., XL-5/W7, 207-214, doi:10.5194/isprsarchives-XL-5-W7207-2015.

Kaneda, A., Nawabi, Y.A., and Yamaguchi, H., 2015. Application of Structure from Motion in Japanese Archaeology, Int. Arch. Photogramm. Remote Sens. Spatial Inf. Sci., XL5/W7, 235-239, doi:10.5194/isprsarchives-XL-5-W7-2352015.

Kwiatek K., Tokarczyk, R., 2014. Photogrammetric Applications of Immersive Video Cameras. ISPRS Annals of Photogrammetry, Remote Sensing and Spatial Information Sciences, vol. 1, pp. 211-218.

Kwiatek, K., Tokarczyk, R., 2015. Immersive Photogrammetry in 3D Modelling, Geomatics and Environmental Engineering,9,2,51-61,AGH University of Science and Technology in Krakow

Lerma, J. L., Cabrelles, M., and Navarro, S., 2015. Fusion of range-based data and image-based datasets for efficient documentation of cultural heritage objects and sites, Int. Arch. Photogramm. Remote Sens. Spatial Inf. Sci., XL-5/W7, 277281, doi:10.5194/isprsarchives-XL-5-W7-277-2015.

Luhmann, T., Tecklenburg, W., 2004. 3-D Object Reconstruction from Multiple-station Panorama Imagery. Panoramic Photogrammetry Workshops, ISPRS Archives, vol. XXXIV-5/W16, Dresden. 